\title{
Fate and removal of pharmaceuticals and personal care products (PPCPs) in a conventional activated sludge treatment process
}

\author{
S. Suarez, F. Omil \& J. M. Lema \\ School of Engineering, University of Santiago de Compostela, Spain
}

\begin{abstract}
The fate and behaviour of 16 Pharmaceutical and Personal Care Products (PPCPs), including fragrances, hormones and medicines with different physico-chemical properties, was assessed during a conventional biological wastewater treatment process in a denitrifying/nitrifying pilot plant. The reactor was fed with a synthetic mixture that reproduced the chemical characteristics of a medium charged urban wastewater with an average composition of $500 \mathrm{mg} / \mathrm{L}$ of COD, $40 \mathrm{mg} / \mathrm{L}$ of $\mathrm{N}-\mathrm{NH}_{4}{ }^{+}$and $8 \mathrm{mg} / \mathrm{L}$ of P-PO ${ }_{4}^{-3}$. Selected PPCPs were spiked to this feed at concentrations between 10 and $40 \mu \mathrm{g} / \mathrm{L}$. The pilot plant has been operated continuously for three years under stable conditions. The occurrence of PPCPs along the different compartments of the pilot plant was determined in a first step by measuring their concentrations in the liquid phase. This was further complemented with detailed mass balances in which the most relevant removal mechanisms during biological treatment have been included (volatilisation, sorption and degradation).

The lowest removal efficiencies were obtained for carbamazepine, diazepam and diclofenac, whereas the highest transformations $(>80 \%)$ were achieved for fragrances, fluoxetine, ibuprofen, naproxen and natural estrogens. Sorption has shown to play an important role in the biotransformation of musk compounds, which had previously shown not to be easily biodegraded, probably by enhancing their retention inside the pilot plant. The removal of the fragrance celestolide was additionally influenced by volatilisation in the aerobic, which supposed up to $45 \%$ of its overall elimination.
\end{abstract}


The SRT of the plant had only an effect on the transformation degree of compounds with a significant sorption potential. The positive effect of operating at warmer temperatures was only significant for two antibiotics, for which an increase in their transformation degree of around 30\% was determined.

Keywords: activated sludge, fragrances, hormones, influence of operational conditions, removal mechanisms, pharmaceuticals.

\section{Introduction}

Most of the current large-scale Sewage Treatment Plants (STPs) are based on Conventional Activated Sludge (CAS) reactors, operated at a Hydraulic Retention Time (HRT) of 4-14 h, which achieve very efficient removal of organic matter. Moreover, in the last two decades, important progresses regarding the simultaneous elimination of organic matter and nutrients have been achieved, in some cases driven by stricter legal requirements. More recently, when trying to improve the quality of water, the main focus shifted from conventional pollutants (organic matter, solids and nutrients) to more specific xenobiotic compounds, some of which were detected at the low $\mu \mathrm{g} / \mathrm{L}$ level and therefore described as micropollutants, which include Pharmaceuticals and Personal Care Products (PPCPs). These observations showed that STPs receive a large number of different trace polluting compounds, although these installations have not been specifically designed to remove them. The reported overall removal rates of PPCPs in full-scale STPs vary strongly and clearly show that their elimination is often incomplete [1]. As a consequence, a significant fraction is discharged within the final effluent into the aquatic environment or sorbed onto primary and secondary sludge, whose deposition on land can be another significant pathway of releasing these substances into the environment.

The removal efficiency achieved for a given micropollutant in a STP will depend on several factors, such as the physico-chemical properties of the compound, the technology used and the operational conditions considered. Parameters such as Hydraulic Retention Time (HRT), Sludge Retention Time (SRT), redox conditions and temperature are thought to affect the removal of PPCPs. The HRT represents the mean time that the liquid phase remains within the treatment process. It was shown to affect elimination of ibuprofen and ketoprofen [2] in a way that lower removal was observed for shorter HRTs. The SRT determines the mean residence time of microorganisms in the reactor, consequently only organisms which are able to reproduce themselves during this time can be retained and enriched in the system. According to this definition, high SRTs allow the enrichment of slowly growing bacteria and consequently the establishment of a more diverse biocoenosis with broader physiological capabilities. For several PPCPs a positive effect on their removal has been observed when working at higher SRT and a critical value for this parameter of $10 \mathrm{~d}$ was identified [3]. Regarding redox conditions and temperature, differences in the removal efficiencies for some PPCPs have been reported $[4,5]$.

The vast majority of data published in the field of removal of PPCPs from wastewaters refer to full-scale STPs, where only the raw influent and final 
effluent are sampled, in order to measure soluble concentrations of the considered PPCPs. Therefore, only the overall removal efficiency including primary and secondary treatment can be determined, without distinguishing between sorption, volatilization or transformation [1]. The aim of the present work was to perform a detailed study of the fate and behaviour of 16 PPCPs in a pilot plant that represents the most common technology used in full-scale STPs. The reactor was fed with a synthetic medium in order to maintain a complete control of the system and to avoid the complexity of real wastewater, such as the presence of conjugates, metabolites or colloidal solids that could interfere with the reliable quantification of the considered substances in the influent. An extensive sampling including the different streams of the system was carried out so as to evaluate the influence of the different redox conditions (anoxic and aerobic) on the transformation of selected micropollutants. Additionally, the effect of temperature and SRT on the performance of the system was analyzed.

\section{Material and methods}

The reactor used is a conventional activated sludge plant divided into a first anoxic and a second aerobic compartment, supplied with a secondary sedimentation tank (fig. 1). The total useful volume of the reactor is $30 \mathrm{~L}$, of which $40 \%$ correspond to the anoxic fraction and the rest to the aerobic compartment.

The pilot plant was inoculated with $2 \mathrm{~g}$ VSS /L taken from full-scale STP based on the Biodenipho ${ }^{\circledR}$ process. The reactor was fed with a synthetic mixture that reproduced the chemical characteristics of a medium charged urban wastewater with an average composition of $500 \mathrm{mg} / \mathrm{L}$ of COD, $40 \mathrm{mg} / \mathrm{L}$ of N$\mathrm{NH}_{4}{ }^{+}$and $8 \mathrm{mg} / \mathrm{L}$ of $\mathrm{P}_{-} \mathrm{PO}_{4}{ }^{-3}$. After a start-up period of 3.5 months, the set of PPCPs listed in table 1 was spiked to the feed at concentrations in the range of 10 to $40 \mu \mathrm{g} / \mathrm{L}$.

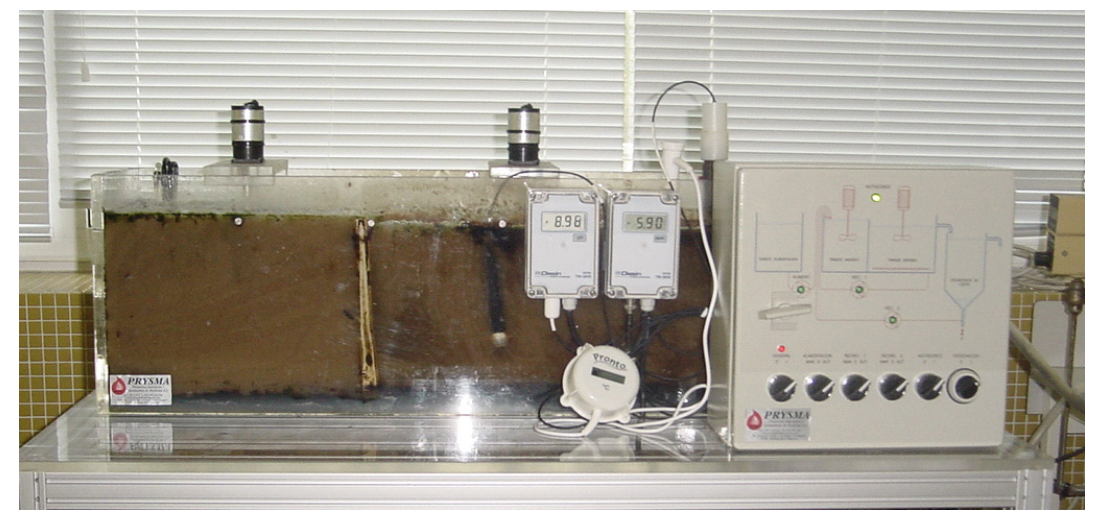

Figure 1: Conventional activated sludge pilot plant. 
Table 1: $\quad$ Concentration of PPCPs in the feed.

\begin{tabular}{|c|c|c|c|}
\hline Compound & $\begin{array}{c}\mathrm{C} \\
(\mu \mathrm{g} / \mathrm{L})\end{array}$ & Compound & $\begin{array}{c}C \\
(\mu g / L)\end{array}$ \\
\hline Anti-depressants: & & Antibiotics: & \multirow{5}{*}{10} \\
\hline Fluoxetine (FLX) & 20 & Trimethoprim (TMP) & \\
\hline $\begin{array}{c}\text { Citalopram (CTL) } \\
\text { Estrogens: }\end{array}$ & \multirow{3}{*}{10} & $\begin{array}{l}\text { Roxithromycin } \\
(\mathrm{ROX})\end{array}$ & \\
\hline$\beta$-Estradiol (E2) & & $\begin{array}{l}\text { Sulfamethoxazole } \\
\text { (SMX) }\end{array}$ & \\
\hline $\begin{array}{c}\alpha \text {-Ethynylestradiol } \\
\text { (EE2) }\end{array}$ & & Erythromycin (ERY) & \\
\hline Anti-inflammatories: & \multirow{3}{*}{10} & Musks: & \multirow{4}{*}{40} \\
\hline Ibuprofen (IBP) & & Galaxolide (HHCB) & \\
\hline Naproxen (NPX) & & Tonalide (AHTN) & \\
\hline Diclofenac (DCF) & & Celestolide (ADBI) & \\
\hline $\begin{array}{c}\text { Anti-epileptic: } \\
\text { Carbamazepine (CBZ) }\end{array}$ & 20 & $\begin{array}{c}\text { Tranquilliser: } \\
\text { Diazepam (DZP) }\end{array}$ & 20 \\
\hline
\end{tabular}

The pilot plant has been operated continuously during 3 years. The operational parameters HRT $(1 \mathrm{~d})$ and composition of the feed were not modified during the whole process. Temperature was not controlled and varied therefore according to the ambient temperature. Consequently, two operation periods could be differentiated, corresponding to moderate temperatures $\left(14-18^{\circ} \mathrm{C}\right)$ and warmer values $\left(18-23^{\circ} \mathrm{C}\right)$. In the case of SRT, the following three ranges were distinguished: $<20 \mathrm{~d}, 20-40 \mathrm{~d}$ and $>40 \mathrm{~d}$. In some cases this variation was due to natural fluctuations of VSS concentrations inside the pilot plant and in the final effluent, whereas in other cases it was manipulated through purges.

Samples were collected from the feed, anoxic and aerobic compartments, external recirculation (from the settler to the inlet) and final effluent. These samples were analysed weekly for conventional operation parameters (COD, solids, nitrogen). Regarding the concentration of PPCPs, two samples per month were taken during the first four months and afterwards the sampling frequency was reduced to one campaign every 1-2 months. Analyses of PPCPs were performed after collecting 2-L samples in glass or aluminium bottles, which were immediately prefiltered (AP4004705, Millipore) and supplemented with a pinch of sodium azide $(\sim 0.3 \mathrm{~g} / \mathrm{L})$. For the analysis of PPCPs sample extraction based on Solid Phase Extraction (SPE) or Solid Phase MicroExtraction (SPME) was used as pre-concentration technique prior to their quantitative determination. 
Liquid or Gas Chromatography coupled to Mass Spectrometry (LC-MS or GCMS, respectively) was used for the final quantification [6-9].

\section{Results and discussion}

\subsection{Pilot plant operation}

Conventional operation parameters of the pilot plant remained stable, being the $\mathrm{pH}$ of the reactor around 8 without any adjustment and the dissolved oxygen concentration in the aerobic compartment always higher than $2.5 \mathrm{mg} / \mathrm{L}$. Sludge concentration inside the reactor increased from the $2 \mathrm{~g} \mathrm{VSS} / \mathrm{L}$ inoculated at the start-up to $4 \mathrm{~g} \mathrm{VSS} / \mathrm{L}$ during the first $140 \mathrm{~d}$, remaining at this value until day 590. After a period of around $130 \mathrm{~d}$ of decrease in sludge concentration due to a significant loss of biomass within the effluent combined with a slower sludge growth rate, it stabilised again at $2 \mathrm{~g}$ VSS/L. The nitrogen mass balance is correctly accomplished in the reactor (fig. 2) and very high removal efficiencies were achieved for both, COD and nitrogen (fig. 3).

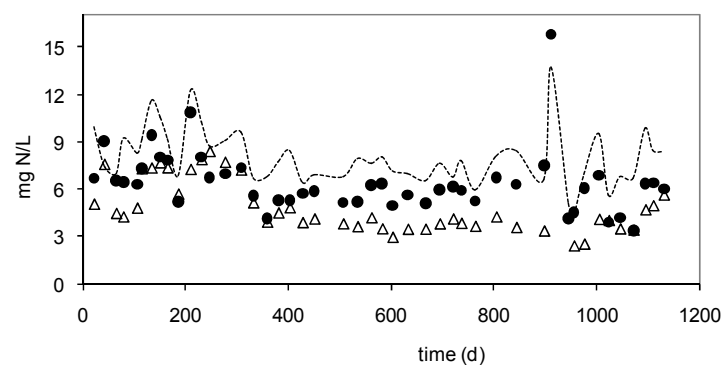

Figure 2: Concentration of nitrogen as ammonium in the anoxic tank experimentally measured $(\bullet)$ and calculated according to dilution $(---)$, as well as nitrate in the aerobic compartment $(\Delta)$.

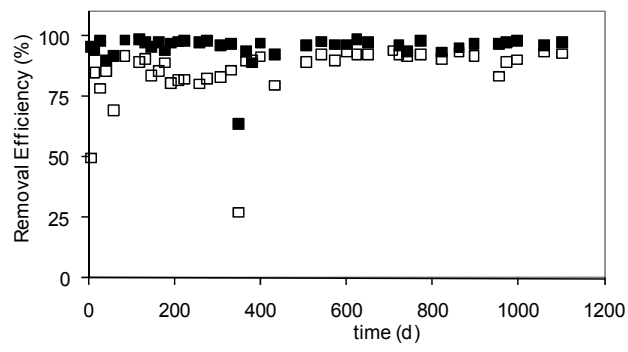

Figure 3: $\quad$ Nitrogen ( $\square$ ) and COD ( $\square)$ removal efficiencies. 


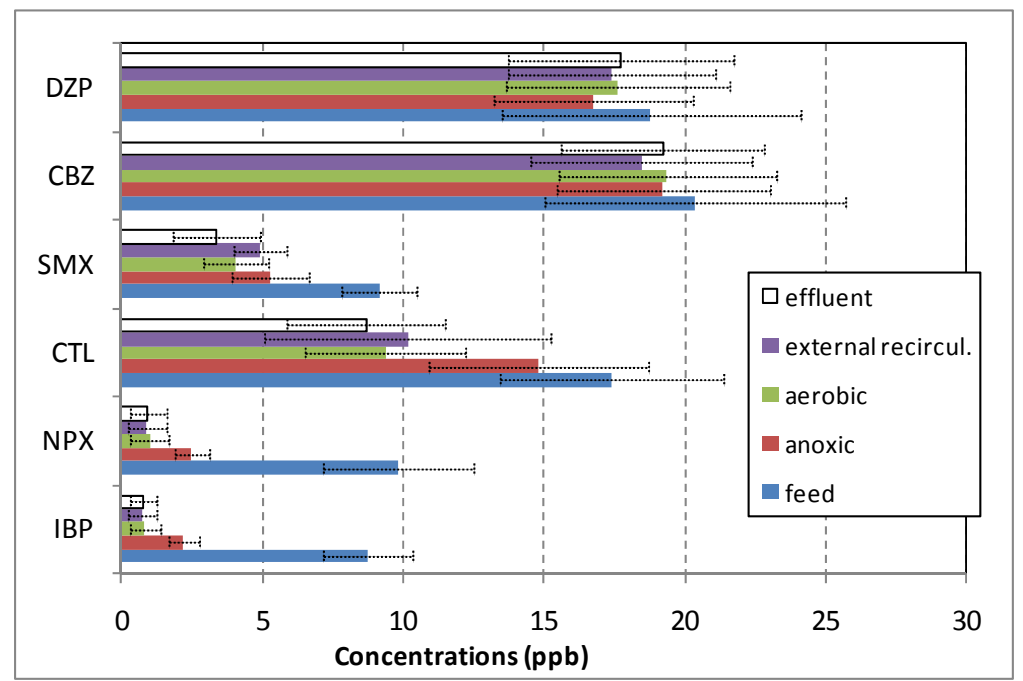

Figure 4: Concentration profile of selected PPCPs inside the pilot plant.

\subsection{Fate of PPCPs along the pilot plant}

The monitoring of the selected PPCPs led to a total of 20 samplings performed over five different points inside the pilot plant. These data have been summarized for some compounds in fig. 4 in which mean concentrations for the whole set of data were considered.

In fig. 4 different behaviours of PPCPs can be observed. On one hand, carbamazepine and diazepam were not significantly removed during the treatment as shown by the flat concentration profiles in fig. 4. In the case of CBZ the low removal percentage achieved after treatment in the pilot plant was consistent with previously reported data, which contributed to propose it as marker for anthropogenic influences on the aquatic environment by Clara et al [10]. Data about the removal of DZP during biological treatment in full-scale STPs are normally not provided due to the fact that concentrations of this substance are frequently below the limits of detection in the influent and effluent of the studied STP $[11,12]$. Considering the sorption potential $\left(\log K_{d} 1.3\right)$ and biological degradation kinetics $\left(\mathrm{k}_{\mathrm{biol}}<0.1\right)$ of this compound, neither sorption nor degradation is expected to be significant, which was actually confirmed in the studied pilot plant. However, there are also some PPCPs, such as IBP and NPX which are removed very effectively during the treatment (removals $>85 \%$ ). These very high removal rates for IBP have been previously observed in activated sludge full-scale STPs of Germany, Spain, England or Japan [13-16]. The performance of the pilot plant regarding NPX removal was slightly better than formerly reported in literature $[11,15,16]$. Finally, CTL and SMX are compounds with intermediate removal efficiencies $(40-60 \%)$. While CTL is 
usually not included in previous works dealing with the removal of PPCPs during sewage treatment, for SMX, eliminations in the range of -138 up to $70 \%$ have been found in previous works $[11,17]$. The variability in these data could be a consequence of working with real wastewaters which can contain not only the parent compound but also metabolites, as for example $N^{4}$. acetylsulfamethoxazole, which can subsequently be transformed back to SMX during biological treatment.

\subsection{Mass balances of PPCPs}

The removal processes considered in the mass balances of selected PPCPs include biological degradation, sorption and volatilisation. The relative contribution of each mechanism to the overall removal depends on the specific properties of each compound, mainly the tendency to be biologically degraded (commonly represented as biological degradation rate constant: $\mathrm{k}_{\mathrm{biol}}$ ), the sorption coefficient $\left(\mathrm{K}_{\mathrm{d}}\right)$ and the Henry's coefficient $(\mathrm{H})$, respectively. The total mass flows in the different streams and compartments of the pilot plant have been represented in fig. 5 for selected PPCPs, including the dissolved, sorbed and volatilised fraction of each compound.

In fig.5, CBZ represents the mass flow of a recalcitrant compound, for which the internal (i.e. from aerobic to anoxic tank) and external recirculation increases the amount of $\mathrm{CBZ}$ that enters the anoxic reactor with respect to the feed. The flat profile between the anoxic inlet and aerobic outlet is a clear indication that no removal of CBZ occurs inside the plant. In the case of IBP, very high removal efficiency is obtained $(>90 \%)$, but transformation only occurred in the aerobic tank of the plant. This dependency of IBP degradation on redox conditions has previously been reported by Zwiener et al [18]. The behaviour of FLX is similar to that of IBP, that is a compound with a negligible sorption tendency although removed to a significant extent by biological degradation (removals $>70 \%$ ), although in this case a partial removal already occurs in the anoxic compartment. Additionally, a slightly positive effect was observed when working at warmer temperatures, with an increase in the removal efficiency of around 10\% (SRT < $20 \mathrm{~d}$ in fig. 5(c) and (d)).

In the case of the fragrances HHCB and ADBI, transformations of around $90 \%$ were reached. The contribution of volatilisation was significant on the total mass flow of ADBI that left the aerobic tank (fig. 5(f)), being its contribution to the overall removal of this compound in the range of $15-45 \%$. The high contribution of sorption onto sludge on the total mass flow of musk compounds HHCB and ADBI in the different streams of the pilot plant is clearly shown in fig. 5(e) and (f), which is related to their strong lipophilic character. Kupper et al [19] reported degradation efficiencies for these fragrances of $40-50 \%$. Additionally, Bester [20] confirmed a partial biological transformation of HHCB by the detection of one metabolite, HHCB-lactone. There are also other authors who associate the removal of fragrances to sorption rather than to biodegradation [21]. 

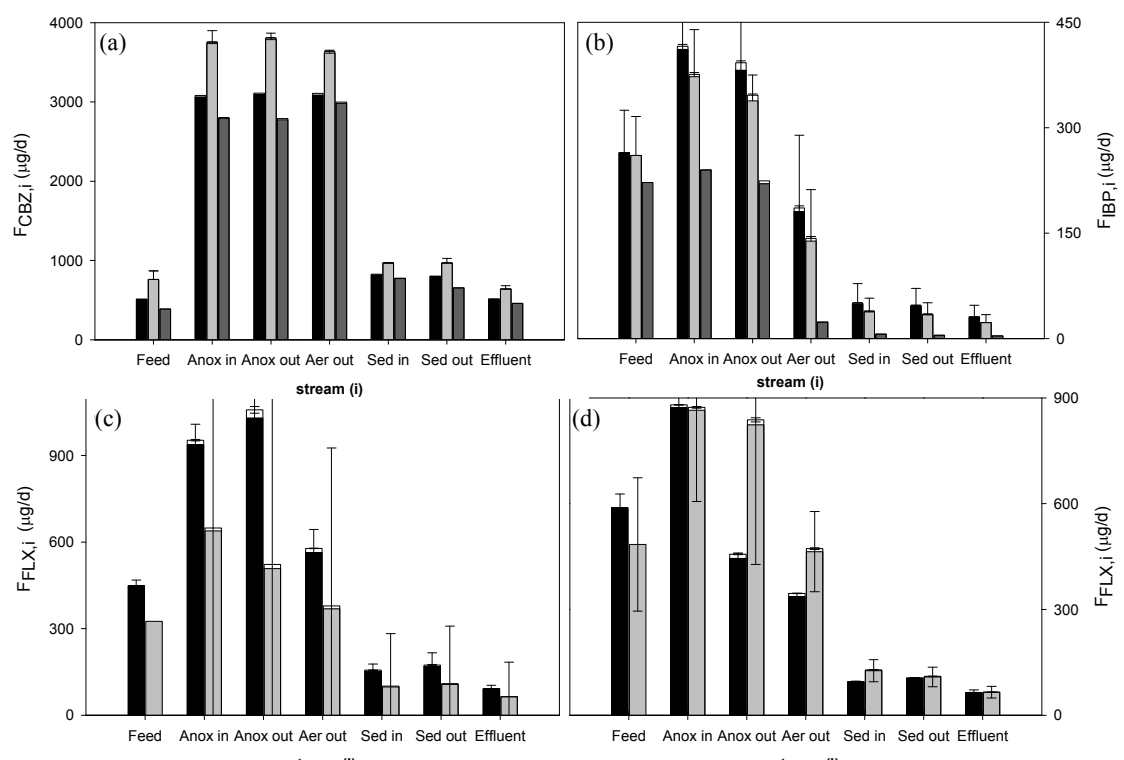

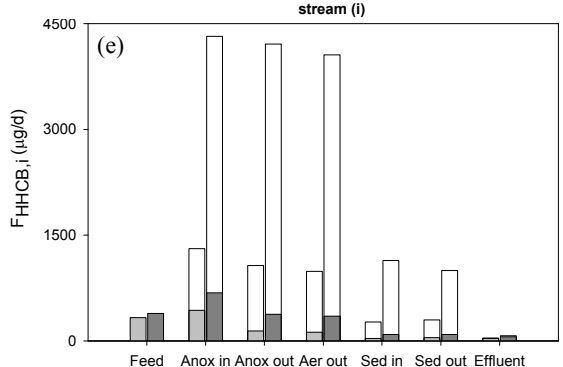

stream (i)

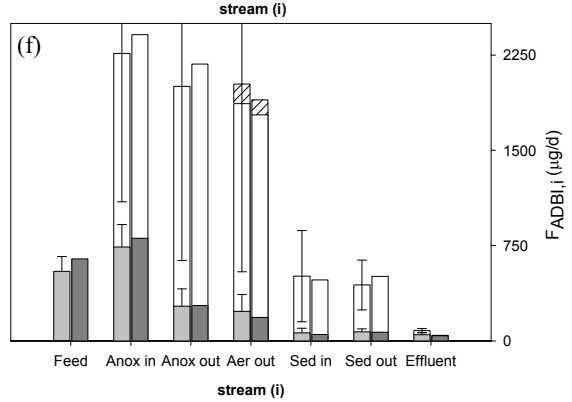

Figure 5: Total mass flow of selected PPCPs in the different streams of the pilot plant working at a SRT of $<20 \mathrm{~d}(\boldsymbol{\square}), 20-40 \mathrm{~d}(\square)$ and $>40 \mathrm{~d}$ $(\square)$. The contribution of sorption ( $\square$ ) and volatilisation ( $\square$ ) is indicated. For FLX data from operation at low (C) and high (D) temperatures are included.

\subsection{Effects of operational parameters on the removal of PPCPs}

Some operational parameters of the pilot plant, such as HRT, composition of the synthetic feed and dissolved oxygen level, have been maintained constant during the whole process, whereas temperature, SRT and the concentration of sludge varied. Accordingly their influence on the process could be evaluated.

$\sqrt{ }$ The SRT of the plant had only an effect on the transformation degree of compounds with a significant sorption potential (estrogens and SMX), presumably because it enhances the retention of the compound inside the plant and consequently its availability for biological degradation. 
$\sqrt{ }$ The positive effect of warm temperature comparing to moderate ones, was observed for E1+E2, FLX, ERY and SMX, being the influence highest for the last compound $(\sim 30 \%)$ and lowest for the first one $(\sim 5 \%)$, that is inversely proportional to the biological degradation rate.

$\sqrt{ }$ The removal of NPX in the studied pilot plant has been increasing from $30 \%$ up to $99 \%$ during the first 300 days of operation, indicating a possible acclimation of bacteria to this pharmaceutical. On the other hand, after day 600 , a clear correlation between sludge concentration in the pilot plant and the efficiency in the elimination of NPX was observed.

\section{Conclusions}

The performance of the pilot plant with regard to its removal efficiency for a set of 16 PPCPs, including musk compounds, hormones and pharmaceuticals of different therapeutic classes, varied strongly from one compound to another. The following groups of compounds can be distinguished on the basis of its behaviour:

$\sqrt{ }$ Very persistent compounds as CBZ, DZP and DCF, which were not significantly removed during the treatment.

$\sqrt{ }$ Compounds with good biodegradability, such as FLX, NPX and IBP, for which high removal of the parent compound was observed, being sorption to the sludge negligible.

$\sqrt{ }$ Musk fragrances, which were efficiently transformed inside the pilot plant, presumably due to their enhanced retention by sorption onto sludge.

$\sqrt{ }$ Compounds moderately removed, such as CTL, SMX, TMP and ERY, for which the transformation degree in the pilot plant was at least $40 \%$, according to their moderate sorption and biodegradation potential.

Some operational parameters, such as temperature, SRT and sludge characteristics have shown to influence the degree of removal achieved in the pilot plant.

\section{Acknowledgements}

This work was supported by Spanish Ministry of Education and Science (MICROFARM project: CTQ2007-66265/PPQ, NOVEDAR_Consolider project: CSD2007-00055 and Research Fellowship). The authors thank Oliver Gans (Austrian Federal Environment Agency) for the analyses of antibiotics.

\section{References}

[1] Suarez, S., Carballa, M., Omil, F. \& Lema, J.M., How are pharmaceutical and personal care products (PPCPs) removed from urban wastewaters? Rev Environ Sci Biotechnol, 7, pp. 125-138, 2008.

[2] Tauxe-Wuersch, A., de Alencastro, L.F., Grandjean, D. \& Tarradellas, J. Occurrence of several acidic drugs in sewage treatment plants in 
Switzerland and risk assessment. Water Research, 39 (9), pp. 1761-1772, 2005.

[3] Clara, M., Kreuzinger, N., Strenn, B., Gans, O. \& Kroiss, H. The solids retention time - a suitable design parameter to evaluate the capacity of wastewater treatment plants to remove micropollutants. Water Research, 39 (1), pp. 97-106, 2005.

[4] Ternes, T.A., Stumpf, M., Mueller, J., Haberer, K., Wilken, R.D. \& Servos, $\mathrm{M}$. Behavior and occurrence of estrogens in municipal sewage treatment plants - I. Investigations in Germany, Canada and Brazil. Science of the Total Environment, 225 (1-2), pp. 81-90, 1999.

[5] Joss, A., Andersen, H., Ternes, T., Richle, P.R. \& Siegrist, H. Removal of estrogens in municipal wastewater treatment under aerobic and anaerobic conditions: Consequences for plant optimization. Environmental Science \& Technology, 38 (11), pp. 3047-3055, 2004.

[6] García-Jares, C., Llompart, M., Polo, M., Salgado, C., Macías, S., Cela, R. Optimisation of a solid-phase microextraction method for synthetic musk compounds in water. Journal of Chromatography A., 963, 277-285(2002).

[7] Lamas, J.P., Salgado-Petinal, C., García-Jares, C., Llompart, M., Cela, R. \& Gómez, M. Solid-phase microextraction-gas chromatography-mass spectrometry for the analysis of selective serotonin reuptake inhibitors in environmental water. Journal of Chromatography A., 1046 (1-2), pp. 241247, 2004.

[8] Quintana, J.B., Carpinteiro, J., Rodriguez, I., Lorenzo, R.A., Carro, A.M. \& Cela, R. Determination of natural and synthetic estrogens in water by gas chromatography with mass spectrometric detection. Journal of Chromatography A., 1024 (1-2), pp. 177-185, 2004.

[9] Rodríguez, I., Quintana, J.B., Carpinteiro, J., Carro, A.M., Lorenzo, R.A. \& Cela, R. Determination of acidic drugs in sewage water by gas chromatography-mass spectrometry as tert-butyldimethylsilyl derivates. Journal of Chromatography A., 985, pp. 265-274, 2003.

[10] Clara, M., Strenn, B. \& Kreuzinger, N. Carbamazepine as a possible anthropogenic marker in the aquatic environment: investigations on the behaviour of Carbamazepine in wastewater treatment and during groundwater infiltration. Water Research, 38 (4), pp. 947-954, 2004.

[11] Carballa, M., Omil, F., Lema, J.M., Llompart, M., Garcia-Jares, C., Rodriguez, I., Gomez, M. \& Ternes, T. Behavior of pharmaceuticals, cosmetics and hormones in a sewage treatment plant. Water Research, 38 (12), pp. 2918-2926, 2004.

[12] Clara, M., Strenn, B., Gans, O., Martinez, E., Kreuzinger, N. \& Kroiss, H. Removal of selected pharmaceuticals, fragrances and endocrine disrupting compounds in a membrane bioreactor and conventional wastewater treatment plants. Water Research, 39 (19), pp. 4797-4807, 2005.

[13] Gomez, M.J., Martinez Bueno, M.J., Lacorte, S., Fernandez-Alba, A.R. \& Agüera, A. Pilot survey monitoring pharmaceuticals and related compounds in a sewage treatment plant located on the Mediterranean coast. Chemosphere, 66 (6), pp. 993-1002, 2007. 
[14] Jones, O.A.H., Voulvoulis, N. \& Lester, J.N. The occurrence and removal of selected pharmaceutical compounds in a sewage treatment works utilising activated sludge treatment. Environmental Pollution, 145, pp. 738744, 2007.

[15] Nakada, N., Tanishima, T., Shinohara, H., Kiri, K. \& Takada, H. Pharmaceutical chemicals and endocrine disrupters in municipal wastewater in Tokyo and their removal during activated sludge treatment. Water Research, 40 (17), pp. 3297-3303, 2006.

[16] Ternes, T.A. Occurrence of drugs in German sewage treatment plants and rivers. Water Research, 32 (11), pp. 3245-3260, 1998.

[17] Gobel, A., McArdell, C.S., Joss, A., Siegrist, H. \& Giger, W. Fate of sulfonamides, macrolides, and trimethoprim in different wastewater treatment technologies. Science of the Total Environment, 372 (2-3), pp. 361-371, 2007.

[18] Zwiener, C., Glauner, T. \& Frimmel, F.H. Biodegradation of pharmaceutical residues investigated by SPE-GC/ITD-MS and on-line derivatization. Journal of High Resolution Chromatography, 23 (7-8), pp. 474-478, 2000.

[19] Kupper, T., Plagellat, C., Braendli, R.C., de Alencastro, L.F., Grandjean, D. \& Tarradellas, J. Fate and removal of polycyclic musks, UV filters and biocides during wastewater treatment. Water Research, 40 (14), pp. 26032612, 2006.

[20] Bester, K. Retention characteristics and balance assessment for two polycyclic musk fragrances (HHCB and AHTN) in a typical German sewage treatment plant. Chemosphere, 57 (8), pp. 863-870, 2004.

[21] Joss, A., Keller, E., Alder, A.C., Gobel, A., McArdell, C.S., Ternes, T. \& Siegrist, H. Removal of pharmaceuticals and fragrances in biological wastewater treatment. Water Research, 39, pp. 3139-3152, 2005. 